\title{
Online Auction using Cloud Computing with Secure Mechanism
}

\author{
P.Anbumani, V.Arunkumar, M.Muthukumar, P.Gowtham
}

\begin{abstract}
In this paper, we at first dismembers the characteristics of the online deal and proposes a general examination framework about the arrangement of online closeout. The standards of this application are, the unpredictable landing system of bidders, the closeouts time, the part measure and the business expenses ought to be considered on Internet trades. In perspective on the properties of online deal and a general examination structure related to the arrangement of online deal, by then we present single-unit and multi-unit perfect closeout models in order to grow the merchant' expected advantages whether the spare expense is open or private demonstrating the favored culmination time of the action, similarly as a discipline work that depicts the cost of slighting the due date. We target cloud work trades that executes in an online way, continues running in polynomial time, gives trustworthiness guarantee, and achieves perfect social welfare for the cloud condition and usage may reflecting the whole that the customer is glad to pay for executing its movement and Moving to those these destinations, we impact the going with extraordinary and new closeout structure methods. At first, we modify the posted assessing auction structure for moving genuine online offers. next, we address the test displayed by sensitive due date confinements through another strategy of preservationist exponential-measure LPs joined with twofold segment prophets. At long last, we make profitable social welfare surmise figurings using the incredible base twofold framework reliant on both $\mathrm{LP}$ duals and Eschol duals. In single-unit closeout, when the seller with open or private hold esteem grabs the maximal expected advantage independently, the perfect open spare expense is higher than the perfect private spare expense. In multi-unit closeout, it is exhibited that the vendor with private spare expense can get the more prominent advantages than the dealer with open spare expense. At long last, numerical outcomes for two cases are given, where we figure the maximal foreseen hard and fast income.
\end{abstract}

\section{INTRODUCTION}

A noteworthy model in distributed computing administrations, Infrastructure-as-a-Service (IAAS) mists is multiplying in the present Internet. An IAAS cloud meets. Clients' Real-time asset requests through virtualization advancements, which pack assets (e.g., CPU, RAM, circle) into virtual machines (VMs). Significant IAAS suppliers today ordinarily offer pre-arranged VM occasions of fixed kinds, with the quantity of sorts expanding throughout the years. For instance, Amazon EC2 presently gives 9 classifications and 39 kinds of VMs. This work focuses on an increasingly reasonable and general setup in online VM sale plan with the accompanying highlights. Each cloud

Revised Manuscript Received on April 12, 2019.

P.Anbumani, Department Of Computer Science and Engineering, VSB Engineering College, Karur, Tamil nadu, India. (anbuanc@ gmail.com)

V.Arunkumar, Department Of Computer Science and Engineering, VSB Engineering College, Karur, Tamil nadu, India.

M.Muthukumar, Department Of Computer Science and Engineering, VSB Engineering College, Karur, Tamil nadu, India.

P.Gowtham, Department Of Computer Science and Engineering, VSB Engineering College, Karur, Tamil nadu, India. client presents an offer containing different alternatives, each requesting a VM collected with a modified heap of assets, which can begin execution at any future time for any predefined span. The cloud supplier acknowledges all things considered one alternative in each offer. In addition, the asset a sythesis of each VM can shift over its term, as per the anticipated need of client outstanding task at hand. The cloud supplier adaptably packs different sorts of assets on heterogeneous physical machines (servers) into the mentioned VMs. Different server cost works under various server operational models are considered in asset portion, which has not been demonstrated in past cloud barters. We configuration barters that expand the social welfare on a total addition of the cloud supplier and the clients (framework productivity), and closeouts that amplify the cloud supplier's net benefit in desire (another reasonable target), while ensuring different properties including honest offering, singular reasonability and computationally effectiveness over the whole framework running range.

Towards better market-based evaluating, barters have as of late been intended for cloud asset allotment, for prearranged VMs of restricted kinds, or for tweaked VMs with client indicated asset packs. The greater part of the systems have concentrated on the one-shot or disconnected setting if the offers are given at the same time. Online VM barters, where bidders travel every which way at wish and assignments and charging choices are to be made on the spot, have just been explored in exceptionally restricted setups.

Wang et al. also, Zhang et al. This paper use an ongoing improvement in basic double online calculation structure and randomized decrease systems, to plan a lot of honest, polynomial time online closeouts for social welfare augmentation or benefit amplification in desire with a decent aggressive check

Xiaoxi Zhang (2018) et al is proposed vitality productive distribution calculations for booking Vim to serve registering undertakings. Sale instruments have been at the point of convergence of late writing on VIM valuing. Onrequest VIM designation through an honest sale is examined, an accomplishment of a higher income for the cloud supplier is appeared.

Ruiting Zhou, et al is proposed particularly closeout segments for cloud resource trading, has pulled in liberal excitement from the investigation arrange, with various VM bargains created in a past couple of years. The most timely VM trades are fundamental in that they are one-round

closeouts and acknowledge 
that the cloud game plans a singular kind of VM, or that VM structures are relative up to direct scaling.

Lena Mashayekhy (2018) et al is proposed harmony having wanted properties, for example, high income. There is a rich group of work on instrument configuration considering static frameworks in which all members are available, and a one-time choice is made to discover an answer. Such frameworks are considered in a disconnected setting, while in online instrument structure, all members arrive and withdraw progressively, requiring settling on choices without having data about what's to come.

Xiaoxi Zhang (2018), et al is proposed dynamic asset provisioning and estimating for VM scaling, this paper proposes a provably productive online closeout instrument. The accompanying down to earth closeout model is examined: Users offer for customized VMs (with modified groups of assets) to use in future. Span, e.g., in view of exact estimation/forecast of asset needs of their occupations.

Benjamin J. Passage (2018), et al proposed the classifier can work fittingly, it ought to be presented using a sensible getting ready dataset. But various locales of research, for instance, dangerous development looks at and computational science, advantage from the availability of a colossal assurance of all around concentrated consistent data, there are no such existing planning datasets for our investigation as a result of a nonattendance of focus on hawking rehearses.

\section{PROPOSED SYSTEM}

The system for distinguishing suspicious online bidders continuously is represented in Fig. 1. We initially recover genuine closeout information from a sale house (for example eBay), and store it as verifiable information for making preparing informational indexes. The grouping module at that point parses the offering history of each sale and utilizations the parsed offering chronicles to figure and standardize values for a gathering of well-characterized credits identified with peddler offering. Every bidder in the informational collection has its very own qualities for such characteristics (for example a bidder's criticism rating). When every one of the bidders are depicted utilizing these properties, a various levelled bunching calculation is connected to the informational index to make sets of gathered bidders. When every one of the bidders are portrayed utilizing these traits, a progressive bunching calculation is connected to the informational index to make sets of assembled bidders. By investigating the attributes of each bunch, we physically mark the groups Real-Time Auction Data Historical Auction Data Auction Data

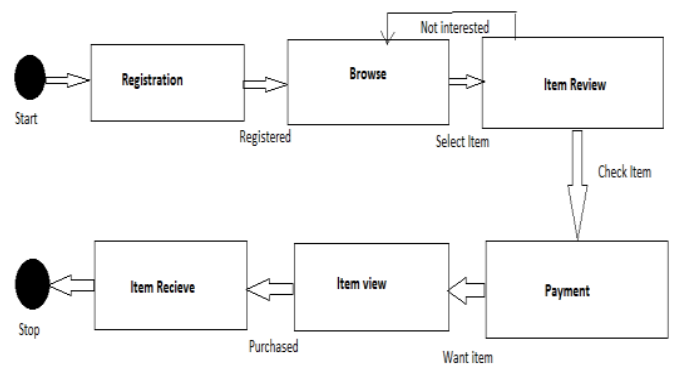

Figure 1 : Process Flow Diagram
Pre-processing Hierarchical Clustering Real-Time SelfAdaptive Classifier (RT-SAC) Cluster Labelling External Verifier for Shill Bidders results suspicious Clustering Module Auction Data Pre-processing normal classify Training Data set initialize Additional Evidence Decision FIGURE 1.

A system for recognizing suspicious online bidders continuously.of bidders as either ordinary or suspicious. For instance, if a bunch's normal number of offers (NB) toward the start of a sale is 9, we name this group as suspicious, since not many bidders place multiple offers toward the start of a bartering. Then again, if a group does not display any suspicious conduct, it is la-belled as typical. For a situation when there is an outline, who is a bidder that exists in its very own gathering that does not show comparative conduct to bidders from some other gatherings, we think about it as a suspicious bidder. At the point when the sum total of what groups have been la-belled, the bunch names are connected to their bidders. The subsequent named bidders comprise a preparation dataset, which can be utilized to introduce the RT.

\section{EXPERIMENT ANALYSIS}

The method fuses four deal types: fixed offer, Amazon, eBay.8, and eBay1. There were twice battling bidders in each bargaining. Each bidder in every deal was permitted private regard openly drawn from a uniform movement some place in the scope of $\$ 6$ and $\$ 10$. The victor of a closeout got his private regard negative the last expense, and a washout got nothing for that bargaining. The last expense was insisted always esteem rule, that is, the bidder who exhibited the most important offer expansion and paid (probably) a little increase $(\$ 0.25)$ over the most critical idea of the opponent, or, if the adversary did not offer, the expense was the base offered of $\$ 1.10$ All deals were inhaled simple, so we can precisely portray 'offering late' without running into bothers of constant time essential administration, for instance, particular differences in creating speed, which may separate effect how late a couple of bidders can offer. It will be sans bother to delineate the particular closeout conditions by first depicting the eBay. 8 treatment. It has two sorts of offering stages, orchestrates 1 (early) and composes 2(late).

Stage 1 is confined into discrete periods. At no matter what, each representative gets an opportunity to make an offer (in the meantime). At each stage climax, the high bidder and current esteem (least increase over second most bewildering offer) are appeared all. Stage 1 closes essentially after a stage at which no player makes an offer. The second period of the eBay. 8 bargains contains a singular period. The bidders have the opening to submit one last offer; it has probability $\mathrm{p}=0.8$ of being adequately transmitted.

In the eBayl condition, the possibility that an offer made in stage two are transmitted effectively is $p=1$, for example arrange 2-offers are transmitted with sureness. Everything else is as on eBay. In Amazon the condition, the shot that an 
offer made in stage two are transmitted effectively is $\mathrm{p}=0.78$, for example arrange 2 -offers are transmitted with assurance.

We are going to utilize following things for upgrade the security of the application,

1. Password imperatives

2. OTP calculation (HOTP)

3. Panoramic view

The riddle key length ought to be least of 9 characters. It improves the multifaceted thought of riddle key from hacking. The secret articulation ought to contain phenomenal characters, numbers, and lowercase and advanced and most essential that isn't has a spot with any English vocabulary words.

Results are gained by taking off slight upgrades in the principal paper by David Lowe. Here, the range of the image isn't duplicated, yet used everything considered for building up a Gaussian pyramid. Stage 1 is separated into discrete periods. At as a matter of course, every agent gets an opportunity to make an offer (in the meantime). At each stage finish, the high bidder and current esteem (least growth over second most surprising offer) are appeared all. Stage 1 closes basically after a stage at which no player makes an offer. The second period of the eBay. 8 bargains contains a single period. The bidders have the opening to submit one last offer; it has probability $\mathrm{p}=0.8$ of being adequately transmitted. This count depicts the resynchronization estimation. Basically, the server reviews the last regard CC of the counter for which a correct mystery key was presented. Exactly when another mystery expression is to be affirmed, the server endeavors $\mathrm{C}+1 \mathrm{C}+1$, $\mathrm{C}+2 \mathrm{C}+2 \ldots$ until one matches, or $\mathrm{C}+\mathrm{wC}+\mathrm{w}$ is pursued some ww called the "window measure".

The arranged target is the going with: the client has a hand-held device which yields the dynamic passwords, one new mystery state for each catch press. The client presses the catch two or multiple times between two login attempts. The server "bets" that the client won't press the catch more than, express, on various occasions before trying to sign in afresh: thusly, the server uses $\mathrm{w}=100 \mathrm{w}=100$. In case you let your 3-year-old nephew play with your HOTP contraption a whole night, chances are that it will be an extreme measure of as-synchronized, and login won't work any longer. The server needs to keep ww little, in light of the way that: The unrefined effect of ww is that, at whatever point the server will recognize ww possible passwords; the higher we is, the higher is the risk that an assailant endeavoring unpredictable passwords may sign in. The computational cost on the server if there ought to be an event of a wrong mystery expression is comparing to us. however, we ought not be too pretty much nothing, in light of the way that an as synchronized contraption proposes extra costs (more work for the help work zone), which should not to happen over and over, even inside seeing hyperactive infant youngsters. The HOTP value is the clear arrangement yield, a d-digit decimal number (without the oversight of driving 0s):

HOTP value $=$ HOTP $(\mathrm{K}, \mathrm{C}) \bmod 10 \mathrm{~d}$

That is, the regard is the $\mathrm{d}$ least gigantic base-10 digits of HOTP.
HOTP is a truncation of the hashed message affirmation code of the counter $\mathrm{C}$ (under the key $\mathrm{K}$ and hash work, $\mathrm{H}$ ). That is, the esteem is the $\mathrm{d}$ least noteworthy base-10 digits of HOTP. HOTP is a truncation of the hashed message validation code of the counter $\mathrm{C}$ (under the key $\mathrm{K}$ and hash work, $\mathrm{H})$.

$\operatorname{HOTP}(\mathrm{K}, \mathrm{C})=$ truncate $(\mathrm{HMACH}(\mathrm{K}, \mathrm{C}))$

Truncation first takes the 4 least huge bits of MAC and utilizations it as a balance, I. truncate $(\mathrm{MAC})=$ extricate $($ MAC, MAC [156:159] $\times 8$ ) That file I is utilized to choose 31 bits from MAC, beginning at bit $\mathrm{I}+1$. Concentrate $(\mathrm{MAC}, \mathrm{I})=\mathrm{MAC}[\mathrm{i}+1: \mathrm{i}+(4 \times 8)-1]$. Note that 31 bit is a solitary piece shy of a 4-byte word. Hence, the esteem can be set inside such a word without utilizing the sign piece (the most huge piece). This is done to abstain from doing measured number-crunching on negative numbers, as this has many varying definitions and executions.

\section{RESULT ANALYSIS}

eBay began as a sale site, yet today has moved to be for the most part a Fixed Price site with under $20 \%$ of exchanges being closeouts and a large portion of those being opened by new dealers who are ignorant that Fixed Price is accessible. On the off chance that you begin your sale excessively low, you may get just a single bidder and be compelled to move beneath your expense or acknowledge a Defect. Such a large number of Defects and eBay will close your record. Numerous potential purchasers need moment fulfillment and are reluctant to endure seven days to discover they lost to a very late expert marksman. We presented another element called sale fixed cost. The purchaser pays the base cost of the item with the goal that miss act will have stayed away from. So we accomplish the undertaking objective with no miss conduct of any purchaser.

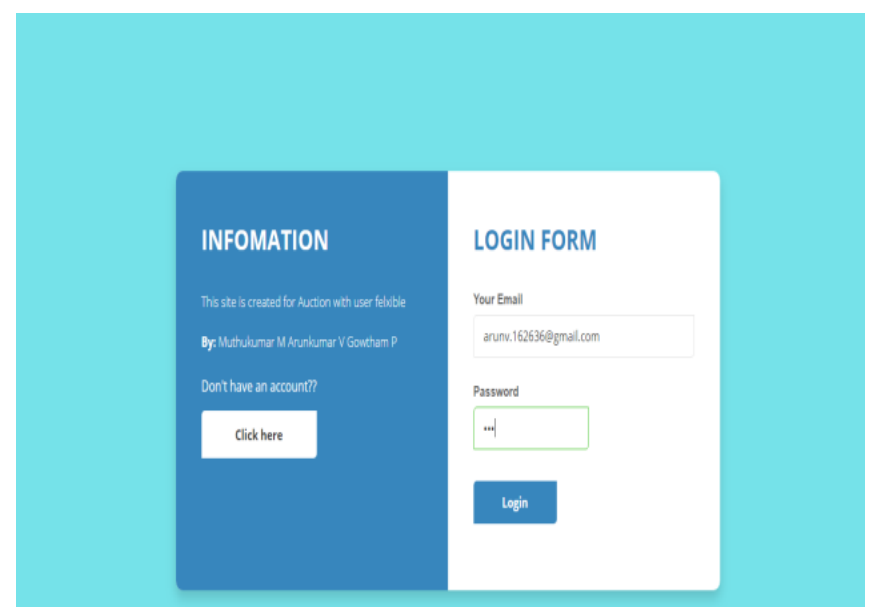

FIGURE 2:- Login page

Impart framework conduct in client's term and count all remotely obvious conduct. Here are the utilization cases for the online closeout framework venture. In our task we acquaint a panoramic see with conquer the current framework disappointment of review the items. What's more, to abstain from deceiving in closeout, a client 
needs to pay essential offer sum can include in a bartering.

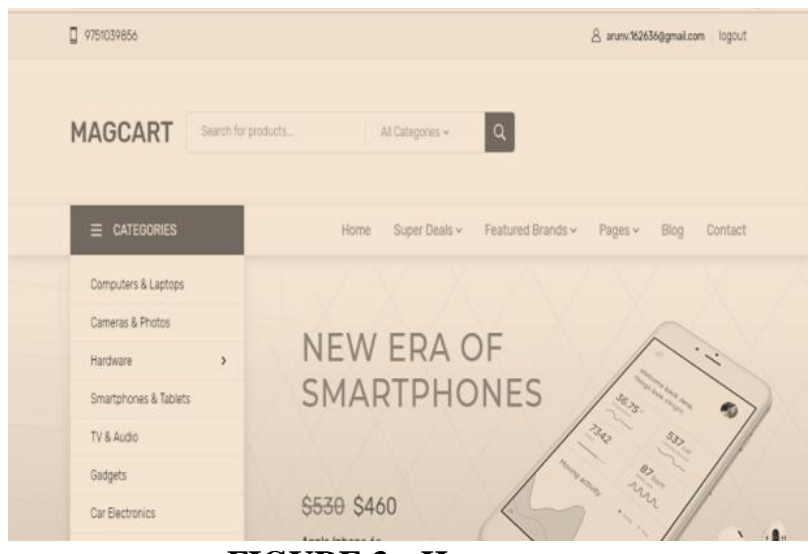

FIGURE 3:- Home page

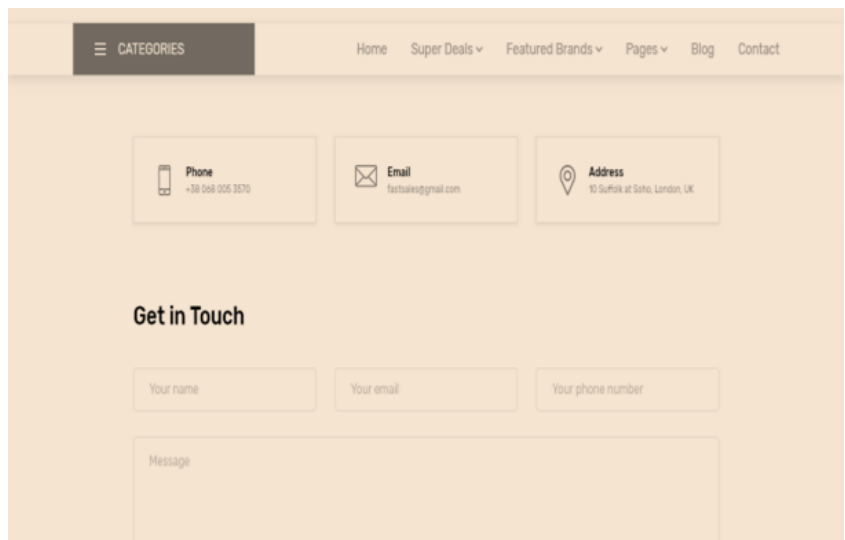

FIGURE 4:- Contact page

\section{CONCLUSION}

On the off chance that we will have online sell-offs with operators purchasing and moving things naturally, we should initially stop and consider such a framework's elements. In a market framework populated by reasonable people, Adam Smith's "Undetectable Hand" discloses to us that the cost of products will approach their minor costs. However, the Invisible Hand alludes just too conventional markets as characterized by financial specialists. In such markets, every result of a given kind is indistinct from others of a similar sort, there are enough gatherings included, and the gatherings demonstration to expand benefit. In an economy of specialists, a portion of the fundamental conditions for an aggressive market may not be met, and costs won't achieve the balance point. For instance, a purchaser operator might be not able dependably to survey the nature of an obtained administration, as Vidal and Duffer showed in connection to the UMDL. Sellers exploit this situation by giving lower quality administrations. Increasingly mind-boggling purchasers may then counter by displaying the dealers' practices. Vendors may thus manufacture models of the purchasers' models of the merchants' models, etc. This circumstance prompts a heightening of displaying levels and to value elements not found in human sales.

\section{REFERENCE}

1. S. Muthukrishnan, L. Aceto, I. Damgård, L. A. Goldberg, M. M. Halldórsson, A. Ingólfsdóttir, I. Walukiewicz, "Internet ad auctions: Insights and directions" in Automata Languages and Programming. ICALP 2008, Berlin, Germany:Springer, vol. 5125, pp. 14-23, 2008.

2. D. S. Evans, "The antitrust economics of multi-sided platform markets", Yale J. Reg., vol. 20, pp. 325, 2003.

3. 3. B. J. Jansen, T. Mullen, "Sponsored search: An overview of the concept history and technology", Int. J. Electron. Bus., vol. 6, pp. 114-131, 2008.

4. 4. B. Edelman, M. Ostrovsky, M. Schwarz, "Internet advertising and the generalized second-price auction: Selling billions of dollars worth of keywords", Amer. Econ. Rev., vol. 97, no. 1, pp. 242-259, 2007.

5. 5. H. R. Varian, "Online ad auctions", Amer. Econ. Rev., vol. 99, no. 2, pp. 430-434, 2009.

6. 6. W. Vickrey, "Counterspeculation auctions and competitive sealed tenders", J. Finance, vol. 16, no. 1, pp. 8-37, Mar. 1961.

7. 7. E. H. Clarke, "Multipart pricing of public goods", Public Choice, vol. 11, no. 1, pp. 17-33, Sep. 1971.

8. 8. T. Groves, "Incentives in teams", Econometrica, vol. 41, no. 4, pp. 617-631, Jul. 1973.

9. 9. A. Abdulkadiroğlu, T. Sönmez, "Random serial dictatorship and the core from random endowments in house allocation problems", Econometrica, vol. 66, no. 3, pp. 689-701, May 1998.

10. 10. V. Conitzer, T. Sandholm, "Complexity of mechanism design", Proc. 18th Conf. Uncertainty Artif. Intell., pp. 103110, 2002.

11. 11. V. Krishna, Auction Theory, San Diego, CA, USA:Academic, 2010.

12. A. V. Goldberg, J. D. Hartline, A. R. Karlin, M. Saks, A. Wright, "Competitive auctions", Games Econ. Behavior, vol. 55, no. 2, pp. 242-269, May 2006.

13. 13. P. Milgrom, Putting Auction Theory to Practice, Cambridge, U.K.:Cambridge Univ. Press, 2004.

14. 14. R. J. Garratt, M. Walker, J. Wooders, "Behavior in second-price auctions by highly experienced eBay buyers and sellers", Experim. Econ., vol. 15, no. 1, pp. 44-57, Mar. 2012.

15. 15. J. Zhang, D. Wen, S. Zeng, "A discounted trade reduction mechanism for dynamic ridesharing pricing", IEEE Trans. Intell. Transp. Syst., vol. 17, no. 6, pp. 1586-1595, Jun. 2016.

16. 16. T. Luo, S. K. Das, H. P. Tan, L. Xia, "Incentive mechanism design for crowdsourcing: An all-pay auction approach", ACM Trans. Intell. Syst. Technol., vol. 7, no. 3, pp. 35, 2016

17. 17. R. B. Myerson, "Optimal auction design", Math. Oper. Res., vol. 6, no. 1, pp. 58-73, Feb. 1981.

18. 18. E. Maskin, J. Riley, F. Hahn, "Optimal multi-unit auctions" in The Economics of Missing Markets Information and Games, London, U.K.:Oxford Univ. Press, pp. 312-335, 1989.

19. 19. R. P. McAfee, J. McMillan, "Auctions and bidding", J. Econ. Literature, vol. 25, no. 2, pp. 699-738, Jun. 1987.

20. 20. P. Klemperer, "Auction theory: A guide to the literature", J. Econ. Surv., vol. 13, no. 3, pp. 227-286, Jul. 1999. 